\title{
Improvement of Labour Productivity and Line Efficiency by Yamazumi Chart: A Case of Leather Products Industry in Bangladesh
}

\author{
Md Mehedi Hasan Tito ${ }^{1}$, Md. Rayhan Sarker ${ }^{2}$ \\ Department of Industrial and Production Engineering, \\ Bangladesh University of Engineering and Technology, Dhaka, Bangladesh ${ }^{1}$ \\ Department of Footwear Engineering, Institute of Leather Engineering and Technology, \\ University of Dhaka, Dhaka, Bangladesh ${ }^{2}$
}

\begin{abstract}
Leather products are highly fashionable items and the second export earning sector of Bangladesh. Many operational tasks are involved during leather products manufacturing. Higher productivity, good quality products, and lead time efficiency are burning issues for this industry. Top management of this industry is striving for higher productivity to gain competitive advantages than other industries. Yamazumi chart is a popular tool to achieve higher productivity; it is used for line balancing through the optimum distribution of workloads among work stations. In this study, the Yamazumi chart technique was applied to improve productivity through line balancing in a leather product manufacturing factory in Bangladesh. The results unveiled that line efficiency was significantly increased from $36 \%$ to $72 \%$. Therefore, it can be inferred from this study that top management of any manufacturing industry can apply this Yamazumi chart technique to improve their firm's productivity.
\end{abstract}

Keywords: Layout, Leather Product Industry, Line Balancing, Line Efficiency, Productivity Improvement, Work Measurement

\section{INTRODUCTION}

Lather products are high value-added manufacturing items. The main benefit of the leather products industry of Bangladesh is the ample supply of hides and skins which are the main raw materials in leather products making. But the major weakness is that standardized manufacturing systems are absent in this sector. Because of many dependencies on manual work, it has a great opportunity to improve labour productivity. Yamazumi chart line plays a significant role as a strategic tool in the re-arrangement of the processing operations to enhance the utilization of a firm's capacity [1]. It is necessary to arrange the production line very effectively and distribute workload in various workstations properly to obtain maximum line efficiency.

The working process of the manufacturing unit can be separated into a set of different operations such as the front part of the unit and the back part of the unit, together which in turn make the complete product. Due to some technological constraints, several tasks must be executed at the same station where no other tasks should be assigned. Other workstations are arranged to increase efficiency at the required production rate to overcome the bottleneck tasks within specified operation time that exceeds the cycle time [2].

This research focuses on the appropriate machine layout, the configuration of assigned manpower, work assisting tools, and re-arrangement of the working sequences. A production line in a leather product industry will be considered as a model line to conduct this study. The labour productivity and line efficiency will be calculated and compared before and after implementing Yamazumi line balancing technique.

\section{PROBLEM STATEMENT}

It is always an expectation of manufacturers to produce more products using fewer resources. There are several challenges inside the leather products manufacturing process such as lots of individual tasks, operating sequences, necessary non-value added tasks, manual work, etc. The most basic operating sections are cutting, sewing, finishing, and packing. The production process is not continuous flow-oriented which is a major cause of inefficiency of production line and workforce. So the lack of proper sequence of operations with optimum line efficiency is the most common problem faced by leather products manufacturers. The application of the Yamazumi chart in line balancing 


\section{International Advanced Research Journal in Science, Engineering and Technology}

Vol. 7, Issue 1 , January 2020

technique in this research will guide the manufacturers to get higher productivity. Yamazumi chart technique can increase the productivity of a company [3]. A common objective for Yamazumi chart line balancing is to minimize the number of work-stations for given cycle time and minimize the cycle time for a given number of work stations [4]. Yamazumi chart is used as a supporting tool to precede workload distribution among workstations towards line balancing. Yamazumi chart is an individual task time bar chart that shows the total cycle time for each operation when performing their process in the production flow [5]. The aim of applying Yamazumi chart line balancing is to balance the overall cycle time for all workstations. An important measure of performance for a production line is the system throughput such as the average number of products produced in a certain time frame.

\section{LITERATURE REVIEW}

\section{Wastage}

Two types of waste are generated in the manufacturing process such as waste which can be seen or measured and waste that cannot be seen or not measured. All defects or breakdown parts are the first types of waste. On the other hand, the second type of waste is generated due to improper transportation of material, poor management, improper working environment and poor knowledge about the process [6]. Productivity can be improved and lead time can be shortened by eliminating such wastes within the overall process through continual improvement. Shortened lead time will help an organization to obtain operational benefits as well as administrative benefits [7].

\section{Line layout}

When some operations are performed in a specified sequence to produce the same product, it is a line layout. The sequence of workflow defines the path from the beginning of the layout to the ending point and from workstation to workstation until the product making is completed. In the most efficient line layout, the sequence of operations and equipment does not need to be changed frequently [8]. Manufacturing plants may have several lines for making the same style or several lines for making different styles depending on the production volume. Line layout does not necessarily mean each machine is different. Several operators and helpers may perform the same operation in a steady flow. The disadvantages of a line layout include potential bottlenecks and an imbalanced workload. Each operation depends on the previously performed task. Downtime, absenteeism, and unskilled operators may interrupt the workflow. To counteract these problems, some operators may need to cross-trained to perform more than one operation, and substitute machines must be readily available for immediate replacement if equipment breaks down. Failure to meet production schedules for any reason may create a need to reroute work, shift personnel, or schedule to add further days [9].

\section{Line Balancing}

Line Balancing (LB) is leveling the workload across all processes in a line to remove bottlenecks [10]. It generally organizes planning of a line layout to have an even and steady production flow. Line balancing rearranges tasks among workstations and used to assign appropriate workforce as required so that each workstation has nearly equal workload. For the effective line balancing performance, each assigned workforce must need to perform work within the specified time duration and repeatedly for each unit of product. Leather product manufacturing requires several sequences of operations to complete product making. Each workstation has a particular part of the total sequence and time should be nearly the same. If one workstation is overloaded and the taken time is over there will be a bottleneck which is not acceptable for the line balancing and it restricts the remaining flow of work. Unequal workload among workstations of a sewing line will lead to an increase of both Works In Progress (WIP) and waiting time, indicating the increase of both production cycle time and cost of a product [11]. That's why the distribution of work should be equalized throughout all workstations with proper arrangement of man, machine and work content to achieve optimum productivity.

\section{Yamazumi Chart}

Yamazumi chart is the most popular line balancing tool used in manufacturing operations. This is the visual representation of workload on each workstation and used as a tool to precede rearrangement of tasks within workstations for line balancing [12]. Yamazumi chart is a man-machine bar chart that shows the total cycle time for each operation when performing operation processes in the production flow [13]. The actual standard cycle time is calculated first to formulate the Yamazumi chart. Secondly, a bar chart is constructed from the accumulated cycle time for one operator. The cycle time is plotted on the vertical axis and the takt time is plotted on a horizontal axis. The aim of applying the Yamazumi chart is to balance the overall cycle time for all the workstations.

\section{Standard Minute Value (SMV)}

The amount of time required to complete a specific job or operation under existing conditions, using the specified and standard method at a standard pace when there is plenty of repetitive work is called SMV [14]. Standard Minute Value (SMV) represents the standard time required for any individual process. It is the amount of time taken by a capable worker to conduct a given task at a standard performance. The SMV includes additional allowances. Different types of allowances are allowed on the production floor such as personal time allowance (relaxation), delay allowances, fatigue 
Vol. 7, Issue 1, January 2020

allowances, machine delay, and anticipated contingencies, etc. SMV is a universal measurement system for time study. Production target, balancing line layout, production planning, operator performance, and operation process efficiency are directly measured by the SMV. In leather products manufacturing, determining a precise SMV is very difficult using traditional work measurement methods because of huge manual works. Moreover, motivation, fatigue and job familiarity affect the performance of the workforce. So the working rate is not constant for all time during the working period [15].

SMV for individual process $=$ Average observed time $\times$ rating $(\%)+$ Allowance $(\%)$

Production target, cycle time, the minimum number of workstations, manpower configuration, labour productivity, and line balancing efficiency are calculated based on SMV. Time study is the most popular and useful method for calculating SMV that is a work measurement technique consisting of careful time measurement of the task. During time study, the observed recorded time is normalized using the performance rating factor. Performance rating is an evaluation method that considers the effectiveness of an operator doing the work. Then it will be applied to calculate the normal time. The Westinghouse system is the most popular used in the assembly line operation process [12]. This rating system describes four factors for rating performance. These are given as follows.

i. Skill: The proficiency of following a pre-determined appropriate method

ii. Effort: Demonstration of the willingness to work effectively and efficiently

iii. Conditions: Workplace condition includes temperature, ventilation, light, noise

iv. Consistency: Evaluation of reliability, stability, uniformity in performance

\section{METHODOLOGY}

A regular article was selected from the sample leather products factory to investigate its current production efficiency and improvement of production efficiency after implementing of Yamazumi chart.

The methodologies are as follows.

1. One leather product industry of Bangladesh will be selected and visited for the study purpose. Firstly, the existing stages of manufacturing will be analyzed and next identified the improvement opportunities for productivity in the production line.

2. Basic time and standard time will be calculated separately by the time study from the cycle time of every operation for different components. After that, the Standard Minute Value (SMV) will be calculated.

3. Process wise hourly production capacity and labor productivity will be calculated by using SMV. The benchmarked production target will be calculated to meet the lead time.

4. Yamazumi chart line balancing technique will be applied and some tasks will be rearranged considering existing bottlenecks in the processes. According to the Yamazumi chart, new production floor layout and manpower allocation will be proposed.

5. New work assisting tools will be developed and implemented to reduce necessary non-value added task time.

6. A new production layout will be applied with a balanced capacity.

7. A current state map will be developed through the collection of information from cutting, sewing, finishing and packing sections of the factory.

8. The current state map will be analyzed to identify the scope of improvement.

9. A future state map will be proposed by the improved processes.

10. Finally, improvement will be compared to the previous state.

\section{DATA ANALYSIS}

The following information has been considered for Yamazumi chart line balancing data calculation.

Working hours per shift $=8$ hours, Available time per day $=480$ minutes, Working time allowance $=10 \%$

Total workable time per day $=480 \times 90 \%=432$ minutes. The daily production target has been set $75 \%$ as achievable based on calculated possible production quantity per day.

Based on observation and evaluation of operators and workers according to the Westinghouse table, performance rating at the sewing section is:

\begin{tabular}{llc} 
Good skill, C2 & $=$ & +0.03 \\
Average effort, D & $=$ & 0.00 \\
Fair conditions, E & $=$ & -0.03 \\
Good consistency, C & $=$ & +0.00 \\
\hline Total & $=$ & $\mathbf{0 . 0 0}$ \\
\hline
\end{tabular}

Normal Time $=$ Average Observed Time $\times$ rating factor 


\section{International Advanced Research Journal in Science, Engineering and Technology}

Vol. 7, Issue 1, January 2020

According to the International Labour Organization (ILO), allowances of the worker at the assembly line are given below.

Table I. Calculation of Allowance Time both for Men And Women
\begin{tabular}{|lll|}
\hline Variable & Men & Women \\
\hline Personal allowance & 5 & 7 \\
Basic fatigue allowance & 4 & 4 \\
Abnormal position allowance & 2 & 3 \\
Bad light & 0 & 0 \\
Atmospheric conditions & 0 & 0 \\
Close attention & 2 & 2 \\
Noise level & 0 & 0 \\
Mental stresses & 1 & 1 \\
Monotony (mental) & 1 & 1 \\
Monotony (physical) & 5 & 2 \\
\hline Total allowance $(\boldsymbol{\%})=$ & $\mathbf{2 0}$ & $\mathbf{2 0}$
\end{tabular}

Standard Time $=$ Normal Time $\times(1+$ Allowance $)$

Labor Productivity and line efficiency before applying Yamazumi chart

Total SMV

No. of assigned manpower

Productive hour percentage

$$
\begin{array}{lll}
=\quad 3040.8 & \text { second } \\
=40 & \text { person } \\
=\quad 90 & \%
\end{array}
$$

Labor Productivity $=\frac{\text { Total number of output per day }}{\text { Number of workers worked }}$

\begin{tabular}{|c|c|c|c|c|c|}
\hline Date & Working hour & Daily manpower & Actual output & Labor productivity & Line Efficiency \\
\hline Day 1 & 8 & 40 & 3 & 0.08 & $1 \%$ \\
\hline Day 2 & 8 & 40 & 10 & 0.25 & $3 \%$ \\
\hline Day 3 & 8 & 40 & 27 & 0.68 & $8 \%$ \\
\hline Day 4 & 8 & 40 & 40 & 1.00 & $12 \%$ \\
\hline Day 5 & 8 & 40 & 90 & 2.25 & $26 \%$ \\
\hline Day 6 & 8 & 38 & 120 & 3.16 & $37 \%$ \\
\hline Day 7 & 8 & 39 & 120 & 3.08 & $36 \%$ \\
\hline Day 8 & 8 & 40 & 120 & 3.00 & $35 \%$ \\
\hline Day 9 & 8 & 40 & 120 & 3.00 & $35 \%$ \\
\hline Day 10 & 8 & 37 & 120 & 3.24 & $38 \%$ \\
\hline Day 11 & 8 & 40 & 150 & 3.75 & $44 \%$ \\
\hline Day 12 & 10 & 40 & 170 & 4.25 & $40 \%$ \\
\hline Day 13 & 10 & 40 & 180 & 4.50 & $42 \%$ \\
\hline Day 14 & 10 & 40 & 180 & 4.50 & $42 \%$ \\
\hline Day 15 & 10 & 40 & 180 & 4.50 & $42 \%$ \\
\hline Day 16 & 10 & 40 & 180 & 4.50 & $42 \%$ \\
\hline Day 17 & 10 & 40 & 180 & 4.50 & $42 \%$ \\
\hline Day 18 & 12 & 40 & 210 & 5.25 & $41 \%$ \\
\hline Day 19 & 12 & 40 & 240 & 6.00 & $47 \%$ \\
\hline Day 20 & 13 & 40 & 270 & 6.75 & $49 \%$ \\
\hline Day 21 & 13 & 40 & 280 & 7.00 & $51 \%$ \\
\hline Day 22 & 13 & 40 & 280 & 7.00 & $51 \%$ \\
\hline Day 23 & 14 & 40 & 330 & 8.25 & $55 \%$ \\
\hline Average & 9.78 & 39.74 & 156.52 & 3.93 & $36 \%$ \\
\hline
\end{tabular}

Line Efficiencey $=\frac{\text { Total output per day } \mathrm{x} \text { SMV }}{\text { Total manpower worked } \mathrm{x} \text { Total productive time per day }} \times 100 \%$

Table II. Daily Labor Productivity and Line Efficiency Before Applying Yamazumi Chart

Before applying Yamazumi chart, the average labour productivity $=3.93$ pieces

Before applying Yamazumi chart, the average line efficiency $=36 \%$ 
Vol. 7, Issue 1, January 2020

\section{RESULTS AND DISCUSSION}

\section{a. Application of Yamazumi chart}

This chart is used to create an image of the structure of the work done by an operator or by a team for a single task. The implementation of Yamazumi chart in line balancing technique in production processes is to assigning tasks to the workstations so that each workstation can perform with a balanced loading. The area of the existing layout was determined and re-arrangement of the working table, machines, a worker sitting positions have been done to draw an improved layout. Considering the working distance, types of machine and efficiency, workers who have extra time to work after completing their works, have been shared or re-allocate their work to complete the bottleneck processes.

$$
\begin{aligned}
\text { Possible Production qty. per day } & =\frac{\text { Total no.of manpower } \times \text { Total workable time }}{\text { Total SMV }} \times 100 \% \\
& =\frac{(39) \times(8 * 3600 * 0.90 \mathrm{sec})}{3040.80 \mathrm{sec}} \times 100 \% \\
& =332.44 \text { pieces } \\
\text { Takt time } & =\frac{\text { Production time available per day }}{\text { Target units per day }} \\
& =8 \text { hrs } \times 3600 \text { sec } / 332.44 \text { pcs } \\
& =86.63 \text { second } \\
& =\frac{\text { Total SMV }}{\text { Takt Time }} \\
& =3040.80 \text { sec } / 86.63 \text { sec } \\
& =35.10 \\
& =36(\text { Rounding up }) \\
\text { Minimum no. of Workstations } & \text { Total SMV } \\
\text { Line balancing ratio } & =\frac{\text { Highest Task time } \times \text { Total no. of Work stations }}{\times 100} \\
& =3040.80 \text { sec } /(116.4 \text { sec } \times 36) \times 100 \\
& =72.57 \% \\
& =332.44 \times 75 \% \\
& =249.33 \\
& =250 \text { pcs }(\text { Rounding up }) \\
\text { Achievable daily production target } & \text { Possible Production qty. per day } \times \text { Estimated } \% \\
& \\
&
\end{aligned}
$$

The number of workstations is determined and the arrangement of tasks among those workstations is done using calculated data. The calculation using the number of workstation formulas will be useful in determining the number of the minimum stations needed for the least number of operators used in a manpower plan which is 39 workers. Manpower configuration starts with the arrangement of the workstations and that's why this step is very important. Single or several tasks are arranged based on cumulative task time in such a way that the sequence of work can be established efficiently.

A change in layout and operation breakdown were done to get an effective flow of operation. Firstly, this layout was implemented by keeping the working table and machine position unchanged. The sequence of work was observed from this trial layout. Then the proposed final layout was developed and implemented throughout the production processes. In the final layout, tasks were distributed ensuring the equal workload among workstations which makes the higher line efficiency from $36 \%$ to $72 \%$ and the target output can be achieved without having overtime. Pre-assembling tasks are started at least one day before the assembling production starts to ensure an adequate supply of required pre-assembled parts to make the complete product through the flow-oriented production system. The calculated line balancing ratio is $72.57 \%$. 
International Advanced Research Journal in Science, Engineering and Technology

Vol. 7, Issue 1, January 2020

Table III. Time Study After Applying Yamazumi Chart

\begin{tabular}{|c|c|c|c|c|c|}
\hline Station & $\begin{array}{l}\text { Observed } \\
\text { time (sec) }\end{array}$ & $\begin{array}{c}\text { Manpower } \\
\text { configuration }\end{array}$ & $\begin{array}{c}\text { Man } \\
\text { power }\end{array}$ & $\begin{array}{c}\text { Station } \\
\text { lead time }\end{array}$ & \begin{tabular}{|c} 
Balance \\
time $(\mathrm{sec})$
\end{tabular} \\
\hline 1 & 47.6 & 0.61 & 1 & 47.60 & 77.84 \\
\hline 2 & 95.2 & 1.22 & 1 & 95.20 & 77.84 \\
\hline 3 & 82.4 & 1.06 & 1 & 82.40 & 77.84 \\
\hline 4 & 44.0 & 0.56 & 1 & 44.00 & 77.84 \\
\hline 5 & 91.6 & 1.17 & 1 & 91.60 & 77.84 \\
\hline 6 & 64.8 & 0.83 & 1 & 64.80 & 77.84 \\
\hline 7 & 100.4 & 1.29 & 1 & 100.40 & 77.84 \\
\hline 8 & 116.4 & 1.49 & 1 & 116.40 & 77.84 \\
\hline 9 & 106.4 & 1.36 & 1 & 106.40 & 77.84 \\
\hline 10 & 104.8 & 1.34 & 1 & 104.80 & 77.84 \\
\hline 11 & 102.4 & 1.31 & 1 & 102.40 & 77.84 \\
\hline 12 & 68.0 & 0.87 & 1 & 68.00 & 77.84 \\
\hline 13 & 98.0 & 1.26 & 1 & 98.00 & 77.84 \\
\hline 14 & 96.8 & 1.24 & 1 & 96.80 & 77.84 \\
\hline 15 & 34.0 & 0.44 & 1 & 34.00 & 77.84 \\
\hline 16 & 87.6 & 1.12 & 1 & 87.60 & 77.84 \\
\hline 17 & 27.6 & 0.35 & 1 & 27.60 & 77.84 \\
\hline 18 & 95.6 & 1.23 & 1 & 95.60 & 77.84 \\
\hline 19 & 44.8 & 0.57 & 1 & 44.80 & 77.84 \\
\hline 20 & 70.4 & 0.90 & 1 & 70.40 & 77.84 \\
\hline 21 & 103.2 & 1.32 & 1 & 103.20 & 77.84 \\
\hline 22 & 80.8 & 1.04 & 1 & 80.80 & 77.84 \\
\hline 23 & 88.0 & 1.13 & 1 & 88.00 & 77.84 \\
\hline 24 & 81.2 & 1.04 & 1 & 81.20 & 77.84 \\
\hline 25 & 57.6 & 0.74 & 1 & 57.60 & 77.84 \\
\hline 26 & 76.4 & 0.98 & 1 & 76.40 & 77.84 \\
\hline 27 & 69.2 & 0.89 & 1 & 69.20 & 77.84 \\
\hline 28 & 62.4 & 0.80 & 1 & 62.40 & 77.84 \\
\hline 29 & 53.6 & 0.69 & 1 & 53.60 & 77.84 \\
\hline 30 & 73.2 & 0.94 & 1 & 73.20 & 77.84 \\
\hline 31 & 83.2 & 1.07 & 1 & 83.20 & 77.84 \\
\hline 32 & 73.2 & 0.94 & 1 & 73.20 & 77.84 \\
\hline 33 & 86.4 & 1.11 & 1 & 86.40 & 77.84 \\
\hline 34 & 146.8 & 1.88 & 2 & 73.40 & 77.84 \\
\hline 35 & 248.0 & 3.18 & 3 & 82.67 & 77.84 \\
\hline 36 & 78.8 & 1.01 & 1 & 78.80 & 77.84 \\
\hline \multicolumn{6}{|c|}{$\begin{array}{ll}3040.8 & 39\end{array}$} \\
\hline
\end{tabular}

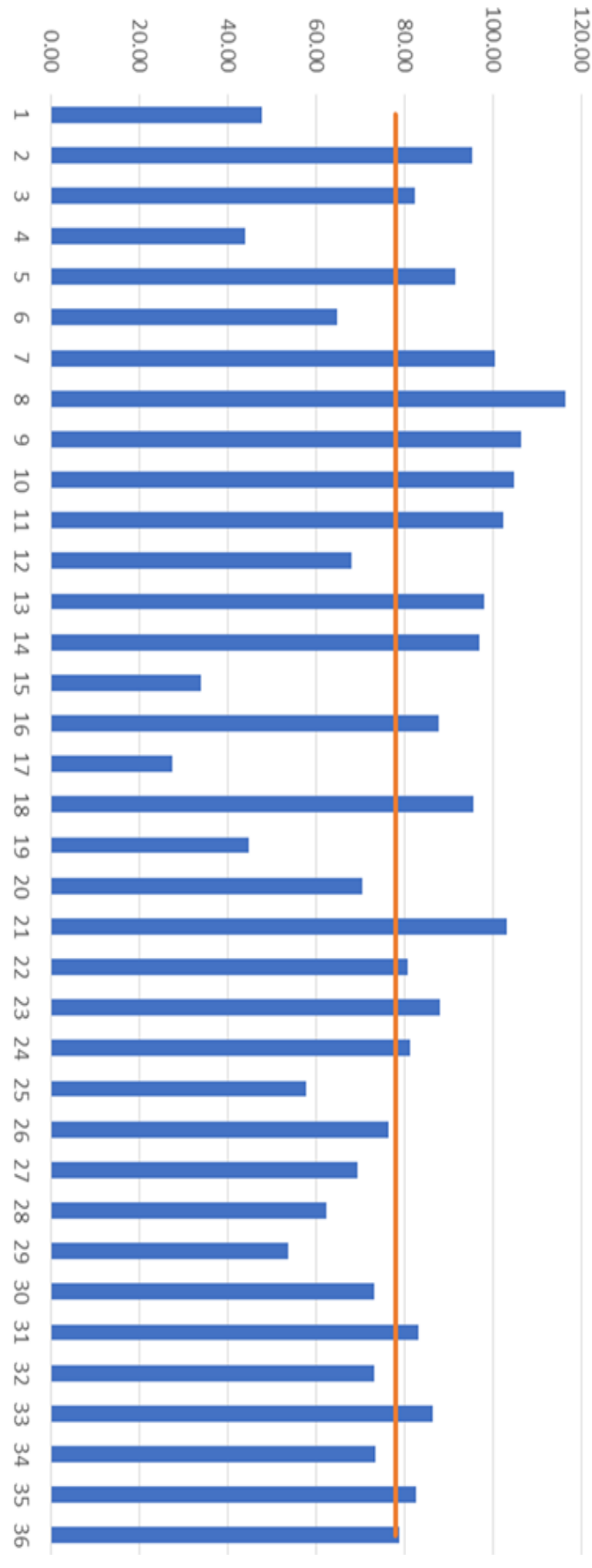

b. Labor Productivity and line efficiency after applying Yamazumi chart

Total SMV

No. of assigned manpower

Productive hour percentage
3040.8 second

39 person

$90 \%$

Table IV Daily Labor Productivity and Line Efficiency After Applying Yamazumi Chart

\begin{tabular}{|c|c|c|c|c|c|}
\hline $\begin{array}{c}\text { Number of } \\
\text { days }\end{array}$ & $\begin{array}{c}\text { Working } \\
\text { hour }\end{array}$ & $\begin{array}{c}\text { Daily } \\
\text { Manpower }\end{array}$ & $\begin{array}{c}\text { Actual } \\
\text { output }\end{array}$ & $\begin{array}{c}\text { Labour } \\
\text { productivity }\end{array}$ & $\begin{array}{c}\text { Line } \\
\text { Efficiency }\end{array}$ \\
\hline Day 1 & 8 & 39 & 160 & 4.10 & $48 \%$ \\
\hline Day 2 & 8 & 39 & 200 & 5.13 & $60 \%$ \\
\hline Day 3 & 8 & 39 & 250 & 6.41 & $75 \%$ \\
\hline
\end{tabular}


International Advanced Research Journal in Science, Engineering and Technology

Vol. 7, Issue 1, January 2020

\begin{tabular}{|c|c|c|c|c|c|}
\hline Day 4 & 8 & 39 & 250 & 6.41 & $75 \%$ \\
\hline Day 5 & 8 & 39 & 250 & 6.41 & $75 \%$ \\
\hline Day 6 & 8 & 39 & 250 & 6.41 & $75 \%$ \\
\hline Day 7 & 8 & 39 & 250 & 6.41 & $75 \%$ \\
\hline Day 8 & 8 & 39 & 250 & 6.41 & $75 \%$ \\
\hline Day 9 & 8 & 39 & 250 & 6.41 & $75 \%$ \\
\hline Day 10 & 8 & 39 & 250 & 6.41 & $75 \%$ \\
\hline Day 11 & 8 & 39 & 250 & 6.41 & $75 \%$ \\
\hline Day 12 & 8 & 39 & 250 & 6.41 & $75 \%$ \\
\hline Day 13 & 8 & 39 & 250 & 6.41 & $75 \%$ \\
\hline Day 14 & 8 & 39 & 250 & 6.41 & $75 \%$ \\
\hline Day 15 & 9 & 39 & 270 & 6.92 & $72 \%$ \\
\hline Day 16 & 9 & 39 & 270 & 6.92 & $72 \%$ \\
\hline Day 17 & 5 & 39 & 150 & 3.85 & $72 \%$ \\
\hline Average & $\mathbf{7 . 9 4}$ & $\mathbf{3 9}$ & $\mathbf{2 3 8 . 2 4}$ & $\mathbf{6 . 1 1}$ & $\mathbf{7 2 \%}$ \\
\hline
\end{tabular}

The average labour productivity after Yamazumi chart line balancing $=6.11$ pieces

The average line efficiency after Yamazumi chart line balancing $=72 \%$

Productivity improvement in a leather products industry largely depends on the improvement of labour productivity. Yamazumi chart line balancing has been found very essential in leather products manufacturing as the workload is distributed among operators effectively throughout the work stations which makes the higher line efficiency and the target output have been achieved without doing overtime. In this research, the level of resources at the bottleneck process has been increased, non-value added activities are avoided by changing work method and layout, similar operations are merged by the application of the Yamazumi chart in line balancing technique. The result shows the increased labor productivity and line efficiency. For the selected style, the original production line had labor productivity of 3.93 labor/day and 36\% line efficiency. Whereas, after applying Yamazumi chart, the labor productivity was recorded 6.11 labor/day and the line efficiency was $72 \%$.

\section{CONCLUSION}

Result-oriented decision making and analysis of operational processes are not followed in many factories. Manufacturers need to implement new techniques in their production operations to increase productivity continuously. Yamazumi chart line balancing is result-oriented and performance-based techniques to increase labour productivity and line efficiency. The analysis shows that the existing production system was not spontaneously flow oriented. The production used to design part by part making process. Flow oriented production can be implemented by Yamazumi chart line balancing in which the complete product output would be possible from the first day of the production planning. This research work has been done with a limited scope. The sample industry is a medium scale leather products manufacturer. In the future, further study may include more different tools and techniques with more working sections with a view to the improvement of productivity. These techniques and improvement analysis may be implemented in several leather products factories to achieve a greater production scale. Then the outcome will be found more realistic and the implementation will be more justifiable.

\section{REFERENCES}

[1]. I. Kucukkoc, A. D. Karaoglan, R. Yaman, "Using response surface design to determine the optimal parameters of genetic algorithm and a case study, International Journal of Production Research, Vol. 51 (17), 2013, pp. 5039-5054.

[2]. G. Tuncel, S. Topaloglu, "Assembly line balancing with positional constraints, task assignment restrictions and station paralleling: A case in an electronics company," Computers \& Industrial Engineering, Vol. 64 (2), 2013, pp. 602-609.

[3]. A. A. Naufal, A. Jaffar, Y. Noriah, N. H. A. Halim, "Implementation of Continuous Flow System in a manufacturing operation," In Applied Mechanics and Materials, Vol. 393, 2013, pp. 9-14.

[4]. Kursad Agpak and Hadi Gokcen, "Assembly line balancing: Two resource-constrained cases," International Journal of Production Economics, Vol. 96 (1), 2005, pp. 129-140.

[5]. D. Sabadka, V. Molnár, G. Fedorko, T. Jachowicz, "Optimization of Production Processes Using the Yamazumi Method," Advances in Science and Technology. Research Journal, Vol. 11 (4), 2017, pp. 175-182.

[6]. D. D. Abhishek Vikas, P. S. Alakshendra, "Lean Manufacturing: An Approach for Waste Elimination," International Journal of Engineering Research \& Technology (IJERT), Vol. 4 (4), 2015, pp. 532-536.

[7]. M. M. Islam, A. M. Khan and M. M. Islam, "Application of Lean Manufacturing to Higher Productivity in the Apparel Industry in Bangladesh," International Journal of Science \& Engineering Research, Vol. 4 (2), 2013, pp. 01-10.

[8]. M. R. H. Shumon, K. A. Zaman and A. Rahman. "Productivity Improvement through Line Balancing in Apparel Industries," International Conference on Industrial Engineering and Operations Management. Dhaka, Bangladesh, January 9 -10, 2010. 


\section{International Advanced Research Journal in Science, Engineering and Technology}

Vol. 7, Issue 1, January 2020

[9]. M. M. Islam, A. M. Khan and M. M. Islam, “Textiles Industries in Bangladesh and Challenges of Growth,” Research Journal of Management Science, Vol. 2 (6), 2013, pp. 1-7.

[10]. N. Kumar and D. Mahto, "Assembly Line Balancing: A Review of Developments and Trends in Approach to Industrial Application," Global Journal of Researches in Engineering Industrial Engineering, Vol. 13 (2), 2013, pp. 29-50.

[11]. U. Prabhuling, V. Keshav, "Assembly line balancing in textile industry," International Journal of Scientific Research Engineering \& Technology (IJSRET), Vol. 6 (4), 2017, pp. 323-330.

[12]. L. P. Sari Hartanti, "Work measurement approach to determine standard time in assembly line," Proceedings of 31st IASTEM International Conference, Pattaya, Thailand, 23rd-24th August 2016.

[13]. D. Sabadka, V. Molnár, G. Fedorko, T. Jachowicz, "Optimization of Production Processes Using the Yamazumi Method," Advances in Science and Technology Research Journal, Vol. 11 (4), 2017, pp. 175-182.

[14]. M. N. Morshed, K. S. Palash, "Assembly Line Balancing to Improve Productivity using Work Sharing Method in Apparel Industry", Global Journal of Researches in Engineering: (G), Industrial Engineering, Vol. 14 (3), 2014, pp. 39-47.

[15]. F. Nabi, R. Mahmud, M. M. Islam, "Improving Sewing Section Efficiency through Utilization of Worker Capacity by Time Study Technique," International Journal of Textile Science, Vol. 4, (1), 2015, pp. 1-8.

\section{BIOGRAPHIES}

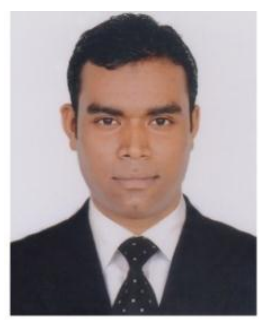

Md Mehedi Hasan Tito, At present, he works as a Production Manager for a renowned footwear and leather product manufacturer in Bangladesh. He completed his master of engineering in manufacturing engineering and management from the Department of Industrial and Production Engineering at Bangladesh University of Engineering and Technology. He completed his B.Sc. Engineering in Leather Product from the University of Dhaka. His research interest comprisesFlexible manufacturing system and process control, Smart and cleaner production, Industry 4.0 and manufacturing strategies, Global supply chain integration

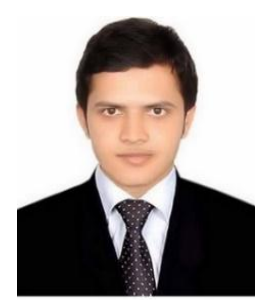

Md. Rayhan Sarker, He is currently working as a part-time Lecturer of the Institute of Leather Engineering and Technology, University of Dhaka. His research interest comprises sustainable manufacturing practices, productivity improvement techniques and comfort properties of shoes. He completed his B.Sc. in Footwear Eng. and M.Sc. in Leather Eng. from University of Dhaka, Bangladesh 